\title{
The EFFECT Of EXPERIENTIAL ENGagement WITH VIRTUAL LEARNING ON UNDERGRADUATE STUdENT SUCCESS
}

\author{
Bronwyn Chorlton ${ }^{1}$, Austin Martins-Robalino ${ }^{1}$, Natalia Espinosa-Merlano ${ }^{2}$, and John Gales ${ }^{1}$ \\ ${ }^{1}$ York University, ${ }^{2}$ University of Toronto \\ bronwynchorlton@gmail.com
}

\begin{abstract}
The purpose of this study is to better understand the effect of undergraduate engineering student engagement with an experiential learning opportunity on academic success in a virtual format. Students in a second year Civil Engineering Materials course that was virtual due to the COVID-19 pandemic were given the option to shift a portion of the final exam weight onto an experiential project. The project consisted of the construction and loading of a small bridge, introducing an experiential component to the virtual course. As a reflective question on the final exam, students were asked to record a brief video testimony related to their motivations and any perceived benefits for participating or not participating in the project.

Of the students who participated in the bridge project, $58 \%$ were characterized as having thorough or above average knowledge and understanding of the graduate attribute indicators, relative to $33 \%$ of students who did not participate. Engagement with the bridge project through experiential learning therefore aligned with strengthened understanding of the graduate attributes, within the restrictions of the remote environment. In planning for future online courses, this study shows a method of engaging students with an experiential activity virtually, its positive effect on academic achievement, and other associated benefits.
\end{abstract}

Keywords: student engagement, experiential learning, online learning, graduate attributes

\section{INTRODUCTION AND BACKGROUND}

In engineering programs, experiential activities (such as laboratories) have traditionally played a large role in student learning and engagement. Experiential learning has been characterized as learning from an experience or learning by doing something. The Experiential Learning Cycle was described by Kolb (1984) as being a cycle of concrete experience (having an experience), reflective observation (reviewing the experience), abstract conceptualization (learning from the experience) and active experimentation (trying what you have learned) [1].
This experimentation leads to another set of concrete experiments. Experiential education can take place in different forms, for example field-based experiential learning that includes internships and co-op placements [2]. Experiential learning can also be classroom based and can be used to relate theory to real-life situations. In engineering education applications, experiential education in the classroom can take the form of laboratory experiments, applied projects, simulations, competitions, or other experiences. The COVID-19 pandemic, however, necessitated many Canadian engineering institutions move to deliver their courses entirely remotely. The virtual course delivery creates challenges in incorporating traditional hands-on and experiential learning opportunities for engineering students.

With regards to further effects of the COVID-19 pandemic on students, university students have reported an increase in stress and anxiety [3]. A study by Son et al. (2020) surveyed 195 students in higher education, and 71\% of respondents reported that the pandemic had increased their levels of stress and anxiety overall. More specifically, Son et al. (2020) noted that $89 \%$ of respondents indicated they had difficulty concentrating, and $82 \%$ were concerned about their academic performance during the pandemic [4]. Chakraborty et al. (2020) also surveyed graduate university students about their opinions of online education during the COVID-19 pandemic and found that $74 \%$ of students agreed that excessive screen time was causing stress and affecting their sleep patterns. Even in years unaffected by the COVID-19 pandemic, there is a need for those who interact with university students to consider student mental health, but the circumstances surrounding the COVID-19 pandemic have made it even more important to consider the mental wellbeing of university students.

It is clear that two factors of the engineering undergraduate student experience that were largely impacted by the COVID-19 pandemic are the availability of experiential learning opportunities, and the challenges surrounding mental health. Students have generally been found to have positive perceptions and see the value of experiential learning [5], while conversely a majority of students have reported they do not learn as well in the 
online environment [6]. As excessive screen time is one factor negatively contributing to student mental health during the COVID-19 pandemic [6], there is a need to explore how experiential activities (away from technology) can be implemented during a remote learning semester. Experiential activities based away from technology and computer screens have the potential to significantly affect student achievement of the course learning outcomes, while minimizing factors that may harm student mental health.

The research herein aims to better understand the effect of undergraduate engineering student engagement with an experiential learning opportunity on academic success in a virtual format. The purpose of this research is to further define the benefits and limitations of one such experiential learning opportunity using a case study.

\section{METHODS}

The case study discussed herein considers students in a second-year Civil Engineering course in Canada that were given the option to complete a project requiring them to create a small bridge out of limited materials and load the bridge to failure. Students that participated were allowed to shift a portion of the weight of the final exam onto this project. On the final exam, students were asked to reflect on their experiences in participating or not participating in the project by characterizing their motivations for participating (or not) as well as describing any perceived benefits (benefits being left broad for the student to interpret). The rationale for allowing students the option to participate in the bridge project was 1) to improve student understanding of material properties and other technical aspects of the course through experiential activity, and; 2) to potentially relieve stress by reducing the weight of the final exam as well as giving students a break from their computers, technology and traditional study activities.

As previously noted, the study herein was meant to better understand the effect of undergraduate engineering student engagement on academic success in a virtual learning format. The overarching method of this investigation therefore consists of examining the correlation of engagement with a case study experiential activity on student achievement of the graduate attributes. Benefits and limitations of such an experiential activity in a virtual format are further identified using student selfreflection testimonies.

The course was comprised of 95 students. At a high level, the course covers topics related to material science, material resilience and sustainability, as well as properties of common structural and transportation building materials. Prior to the COVID-19 pandemic, the course was taught in person with three hours of lecture per week, one hour of tutorials, and two hours of weekly laboratory sessions. The laboratory sessions presented an experiential component to the course and were centred around the mechanical properties of the materials that were being studied in class. For the Fall 2020 version of the course, the course was entirely virtual. Students had two hours of asynchronous and one hour of synchronous lecture per week, as well as one hour of synchronous tutorial and two hours of synchronous laboratories. The virtual laboratories were designed to achieve the same learning outcomes as the in-person laboratories and are discussed in greater detail in planned studies by the authors.

The design of the virtual Fall 2020 version of the course was influenced by data that had been collected by other researchers regarding successes and challenges during the Winter and Spring/Summer 2020 semesters earlier in the year. Students at seven American private and public institutions were surveyed $(n=3006)$, with participating institutions receiving the collected data specific to their institution and relative to the cumulative data [7]. Survey results can be obtained by contacting participating institutions, however for this study the data were provided to the course instructor as part of their international teaching activities of a specialized lecture series. The institution from which the data was predominantly examined is largely comprised of engineering students. Takeaways from this previously collected data included that students reported that they did not learn as well they would have in a physical classroom, and that many students felt that they were not able to balance their social/emotional needs with their coursework [7]. These studies emphasized the importance of considering student social/emotional needs in the course design and incorporating activities that would be included in a physical classroom version of the course.

In terms of requirements for the optional bridge project, students were asked to create a bridge using only popsicle sticks, dental floss, toothpicks, and white glue. Specifications were outlined with respect to the required clear span, span height, and span opening. Weight ranges of the final bridge were also specified. Students were further asked to create a 5-10- minute recorded presentation explaining the design and engineering behind their bridge, and then demonstrate the loading of the bridge to failure, reporting the final failure load. The bridge project was assessed on the originality and aesthetics of the design, the quality and spirit of their presentation, their loading demonstration, and their justification for their predicted modes of failure. Most of the criteria was meant to enhance course learning outcomes, however the 'spirit of the presentation' criterion was meant to encourage 
students to have fun with the project as well showcase their interests and personalities. Student submission of the bridge project consisted of their recorded presentation.

The project was designed to be cost efficient for students. The cost of 1000 popsicle sticks, $100 \mathrm{~m}$ of dental floss, and $1 \mathrm{~L}$ of white glue was estimated to be around \$20CAD, with these materials being readily available in stores and online. While the students purchased the materials themselves, the costs associated with the course were reduced overall from previous years as the students were not required to obtain personal protective equipment for the laboratory sessions (where minimum cost would have been approximately $\$ 100 \mathrm{CAD}$ ).

The optional bridge project was inspired by the Troitsky Bridge Building Competition, an undergraduate student competition where teams from different universities create a bridge using popsicle sticks, dental floss and white glue within a time limit, and load the bridges to failure (the interested reader can look into the full requirements and evaluation procedures [8]). The origins of the Troitsky Bridge Building Competition stem from Civil Engineering coursework at Sir George Williams University (that would later become Concordia University). Students in a bridge design class were asked by their professor (Dr. Michael Troitsky) to design and build a bridge model using wood and glue. Over time, the project turned into a competition for Concordia students and eventually opened to institutions across Canada [8]. The implementation of the bridge project back into a single Civil Engineering course returns an adaptation of the project to its origins.

The reasoning for giving the students the option to participate in the bridge project was mainly to reinforce concepts taught in the course, and to reduce stress. By giving students the option to shift weight from the final exam to the bridge project, the intention was to reduce stress surrounding the final exam, which is a traditionally stressful time for students during a normal year, combined with the effects of the pandemic on student mental health had the potential to be very overwhelming. Moreover, the project was hands-on and experiential, and was therefore meant to be somewhat of a stress release by providing students with an excuse to take a break from their studies and do something creative and hands-on.

With regards to reinforcing graduate attributes covered by the course, the students needed to rely on their understanding of material properties to strategically create a design that they felt could support the greatest amount of load while keeping the weight as minimal as possible. The use of popsicle sticks in particular draws upon their knowledge of the material properties of timber - a material that has been identified as beneficial for program graduates to have increased knowledge of, as timber design becomes more prevalent in cities around the world [9]. Further, the project was meant to reinforce graduate attribute indicators as outlined in Table 1 using experiential learning. Table 1 highlights graduate attribute indicators assessed by both the project and by the final exam.

Table 1. Graduate attributes assessed by both the bridge project and the final exam.

\begin{tabular}{|l|l|}
\hline \multicolumn{1}{|c|}{$\begin{array}{c}\text { Graduate } \\
\text { Attribute }\end{array}$} & \multicolumn{1}{c|}{ Indicator } \\
\hline $\begin{array}{l}\text { Knowledge } \\
\text { Base for } \\
\text { Engineering }\end{array}$ & $\begin{array}{l}\text { Understand the physical, chemical, } \\
\text { and mechanical properties of } \\
\text { various civil engineering materials }\end{array}$ \\
\hline $\begin{array}{l}\text { Problem } \\
\text { Analysis }\end{array}$ & $\begin{array}{l}\text { Understand and calculate stresses } \\
\text { and strains experiences by various } \\
\text { materials due to loads }\end{array}$ \\
\hline Design & $\begin{array}{l}\text { Conceive design solutions to solve } \\
\text { the defined problem }\end{array}$ \\
\hline $\begin{array}{l}\text { Communication } \\
\text { Skills }\end{array}$ & $\begin{array}{l}\text { Prepare a professional laboratory } \\
\text { report including engineering charts, } \\
\text { tables, graphs and diagrams to } \\
\text { present information effectively }\end{array}$ \\
\hline
\end{tabular}

A question was added to the final exam asking students about their participation or non-participation in the bridge project. The exact wording of the exam question is found in the Appendix. In general, students were asked which factors motivated them to participate or to not participate in the project. Students who participated were further asked if they believed that the project contributed to their understanding of the course material, and if there were any additional benefits in participating in the project. Submissions were to consist of a one-minute video recording of themselves.

Analysis of the video testimonies recorded by the students consisted of watching the videos, and identifying factors mentioned by the students. Where students mentioned more than one motivation or benefit, all factors mentioned were included in the analysis equally. Categories for factors that contributed towards students' motivations for participating/not participating as well as perceived benefits were created by counting the number of students who used similar phrasing in their testimonies. The categories related to mental health included student mentions of reducing stress, enjoying using hands on activities to relax, or doing similar activities as a hobby.

The technical portion of the final exam pertained to the student's comprehension of the course content, and included components of their knowledge base, problem analysis, design, and communication skills. This portion of the final exam was assessed relative to the graduate attribute indicators. 
In addition to submitting the bridge project as a part of the course, students were also able to submit their bridge presentation as a part of a competition hosted by the University's Civil Engineering Student's Association group. The project was designed to meet the requirements of the student association's competition, and the competition was also open to students not enrolled in the course. Performance in the student association's competition led to the creation of a team for the official Troitsky Bridge Building Competition for the year.

\section{RESULTS AND DISCUSSION}

Overall, 62 students $(65 \%)$ chose to participate in the bridge project, and 33 students (35\%) opted not to participate.

\subsection{Effect of Engagement in Bridge Project on Student Achievement}

The technical component of the final exam was marked in relation to the graduate attribute indicators defined in Table 1. As such, Fig. 1 is intended to convey how well students who participated or did not participate in the bridge project were successful in achieving the graduate attribute indicators. Students who received an A on this portion of the exam had strong achievement of the graduate attribute indicators, students who received a B had above average achievement of the graduate attribute indicators, and so forth. Students that did not achieve the graduate attribute indicators received an $\mathrm{E}$.

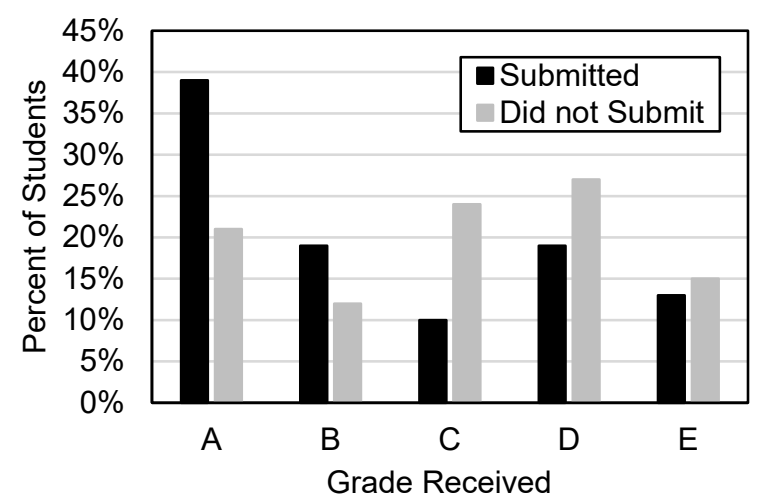

Fig. 1. Achievement of graduate attribute indicators among students who submitted and who did not submit the bridge project.

Students who were sufficiently engaged in the course to participate in the bridge project better demonstrated the graduate attributes indicators, as $58 \%$ of submitters scored an A or a B compared to $33 \%$ of non submitters.

While the grade received by students as shown in Fig. 1 is somewhat subjective to the person assessing the exam question, steps were taken to reduce bias. This included not marking the exam and the project together, and when marking the exam, not checking the students existing grade or whether they chose to participate in the bridge project.

\subsection{Motivations and Benefits of Students that Participated}

One of the final exam questions asked students about their motivations for participating or for not participating in the bridge project.

From reviewing student video responses, generalized categories of motivations could be made. It should be noted that these categories were not presented to students for a selection style response, but rather the questions were open ended with many students crediting the same motivations. It should be further noted that students were asked to name at least one motivation, but many students discussed multiple different motivations, and as such the number of responses does not align with the number of students who participated in the bridge project. Responses of students who participated in the bridge project are summarized in Fig. 2.

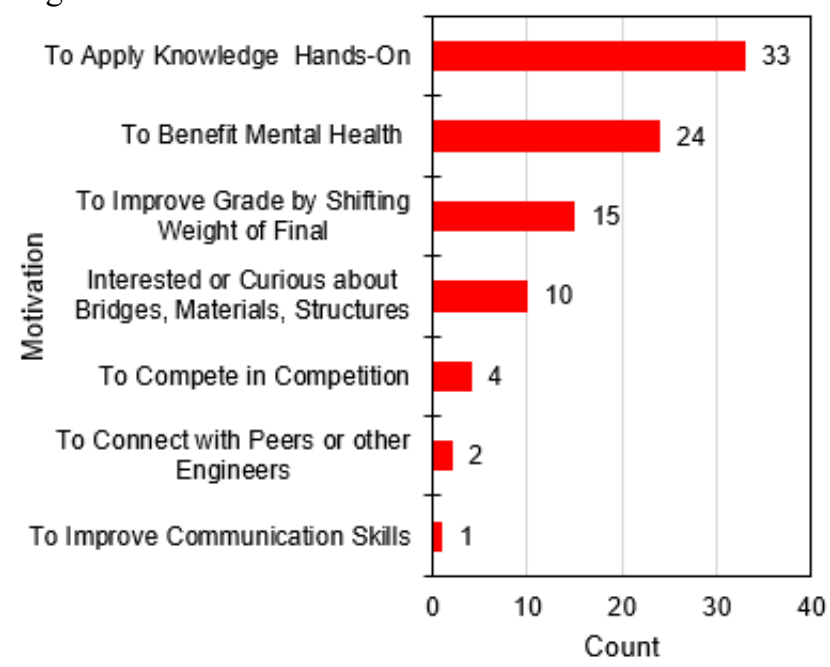

Fig. 2. Student motivation for participating $(n=65)$.

The most common motivation was that students wanted to try applying their knowledge in a hands-on application (51\% of students that participated commented that this contributed to their motivation). The high level of motivation to participate in a hands-on application could have partially been a product of the entirely virtual semester - if students were completing in person laboratories and classes, they may have had felt less of a need to do something hands-on. Nevertheless, this motivation reinforces the desire of students for experiential learning opportunities. 
24 students, or $40 \%$ of those that participated, commented that they chose to participate for reasons relating to mental health - which included that doing this style of activity is relaxing or fun for them, or that stress surrounding the final exam was reduced. 15 students $(23 \%$ of those who participated) distinctly indicated that they wanted to participate to shift a portion of the weight of their grade from the exam to the project to improve their overall grade, and not just to reduce stress surrounding the final exam.

Ten students ( $15 \%$ of those that participated) indicated that they wanted to participate simply because they were interested or curious in bridges, materials, or structures, and wanted to use this project as an opportunity to learn more. Four students (6\% of those that participated) participated distinctly to submit their project to the student association's version of the bridge competition, for an opportunity to potentially compete in the national Troitsky Bridge Building Competition. Peer interactions have previously been identified as a source of discouragement and intimidation for engineering students [10], so promoting friendly peer interactions through student competitions and events is valuable in fostering positive experiences in undergraduate engineering programs.

Two students wanted to use the project to connect with other engineers, or their peers - this included discussing strategies with their peers, and connecting with other engineers that included family members for advice which was encouraged and allowed in the rules of the project. Finally, one student wanted to participate to take the opportunity to practice their presentation and communication skills.

Furthermore, students were asked to comment on any benefits they experienced from participating in the bridge project that do not directly tie into the content covered by the course material. The results of the student responses are summarized in Fig. 3. It should be noted that the motivations of the students do not directly align with the perceived benefits. It is assumed that many students felt that if they mentioned something as a motivation, they did not need to confirm that it was a benefit (e.g. the same students did not characterize reduced stress surrounding the final exam as both a motivation and a benefit).

25 students (38\% of those who participated) noted that they strengthened their project management and design skills. Examples of this cited by students were that they were thinking about schedules they needed to keep to in order to finish by the deadline and thinking of their rationale as to why they chose a particular design over another. 18 students (28\% of those who participated) explained that participating in the project benefitted their mental health to some extent, either by reducing the stress of the final exam or by having fun and relaxing during the creation of their bridge.

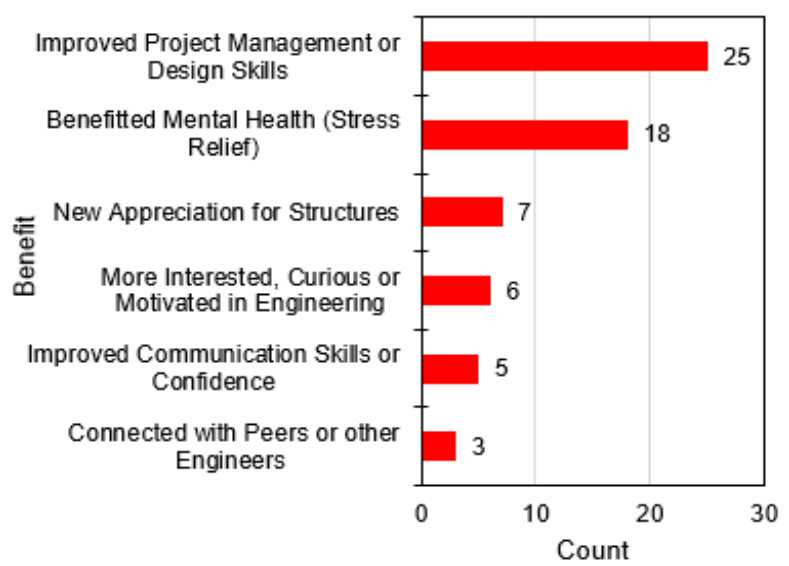

Fig. 3. Student reported benefits of participation, exclusive of enhancing understanding of course materials $(n=65)$.

Seven students (11\% of those who participated) commented that they have a new appreciation for structures or are thinking about structures differently, examples included contemplating the structural design of bridges they see in their every day lives. Similarly, six students ( $9 \%$ of those who participated) discussed how the bridge project made them more curious or interested in engineering topics, or that they felt more motivated to study or practice engineering. Five students ( $8 \%$ of those that participated) indicated that they felt their communication skills improved, or that they were more confident in presenting.

Finally, three students noted that they had the opportunity to connect with others. These students explained that the project gave them an opportunity to work with other engineers - usually friends or family - where they would not have had otherwise dedicated time to spend with friends or family.

\subsection{Motivations of Students that did not Participate}

33 students chose not to participate in the bridge project. Their responses, when asked on the final exam of their motivations to not participate, are summarized in Fig. 4. Students were asked to provide at least one motivation.

Nine students (27\% of those who did not submit) indicated that they might have liked to participate but could not make the time or meet the deadline. A further nine students indicated that they strategically chose not to participate to focus their time on studying for the final exam.

Three students ( $9 \%$ of those who did not participate) explained that they were not confident in their ability to 
make a quality bridge or presentation, and similarly a further two students indicated they did not want to shift a portion of the weight of the final exam to the project where the underlying motivation is not specified but could possibly be attributed to some of the other motivations specified for not participating (e.g. low confidence).

Two students indicated they could not obtain resources needed to participate in the bridge project, and one student indicated that they had competed in a similar project in the past and did not see the value in creating another bridge.

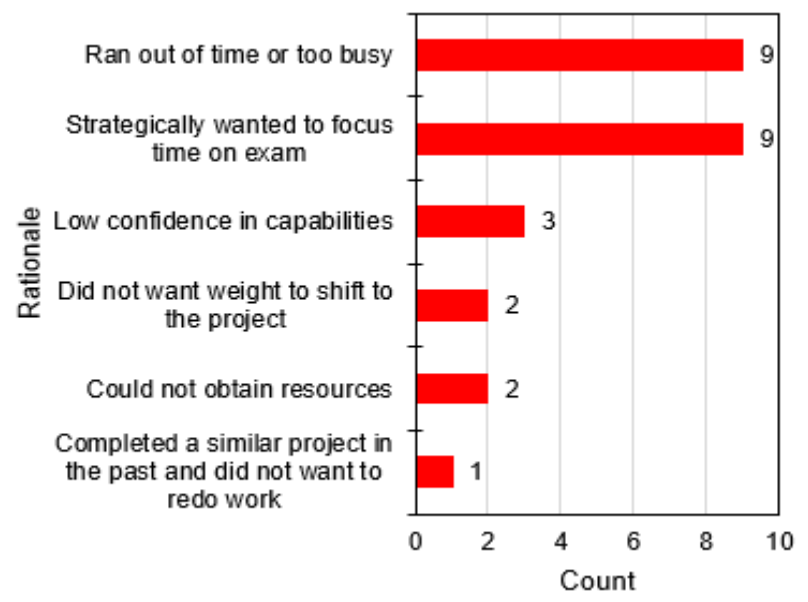

Fig. 4. Rationale presented by students for not participating in the bridge project $(n=33)$.

\subsection{Further Adaptations}

Given the circumstances surrounding the COVID-19 pandemic, the bridge project offered an experiential opportunity for engaged students. Students who were sufficiently engaged with the course to participate in the bridge project reported numerous benefits related to their mental health and demonstrated a stronger understanding of the graduate attributes than students who were less engaged and chose not to participate.

In future iterations of this course - or similar courses adaptations of the project could be considered. Considering that overall, students that were engaged also demonstrated a better understanding of the graduate attributes, the rationale for students who did not participate could be analyzed in future iterations to make the project more accessible and encourage participation. This might include introducing the project as early as possible in the semester such that students can allocate time.

Some students also indicated that they could not obtain the resources needed to participate in the project. Course packs could be mailed out to students at the beginning of the semester and include the materials they need, eliminating the need for students to source materials themselves and ensuring each student is able to obtain the required materials. Considering the cost of the materials is estimated to be less than \$20CAD per student, the cost of distributing materials to students should be manageable for many schools, especially in years where in person laboratory sessions can not be held. Though costs of shipping and administrative duties would need to be considered, traditional laboratory sessions for this particular course have in the past involved the design, creation, and loading of various civil engineering materials, in which the cost of materials alone has cost more than \$20CAD per student.

Upon the resumption of in-person classes and laboratories, there is still value in similar projects. All of the benefits and motivations discussed in Figs. 2 and 3 will still hold true should the class be held in an in-person format, though the extent of the motivations and benefits might be altered, and new motivations and benefits may be introduced. A course held in person would have even more possibilities as to how such a project could be carried out, for example it could be adapted as a group project. An in person variation of the project could also further some of the benefits previously mentioned, for example there is the opportunity for greater connection between peers or other engineers, in brainstorming ideas and having an activity to do together on the day of testing. The in-person variation could also further strengthen communication skills, by providing students a low-stress opportunity to present. These and other possible enhanced benefits of an in-person variation should be addressed by future research.

\section{CONCLUSION}

The purpose of this study was to better understand the effect of student engagement on academic success in undergraduate students in a virtual learning format, by considering a case study looking at engagement with an optional experiential project within a Civil Engineering Materials Class. Findings from the study showed that students who engaged through participation in the optional project demonstrated a better understanding of the course graduate attributes than students who were not engaged enough to participate. Engaged students that submitted the bridge project were nearly twice as likely to demonstrate an exceptional or above average understanding of the graduate attribute indicators on the final exam $58 \%$ of students who submitted the project vs. $33 \%$ of students that did not).

Beyond enhancing student understanding of the course material, the bridge project was intended to also benefit mental wellness to some extent. Understanding that the 2020 academic year was especially stressful for students due to the COVID-19 pandemic, the bridge project was 
meant to reduce stress by giving students the option to shift weight from the final exam onto the project, as well as by giving students an excuse to take a break from their computers and do something hands-on. These benefits were appreciated by students, with $37 \%$ of students who participated noting that mental wellness was one of their primary motivations for completing the bridge project, and $28 \%$ of students noting that upon reflection, improvements to mental wellness were a benefit to participating.

Limitations of this study include that the project was optional for the students. If the project had not been optional, it would have been possible to get the opinions of the entire cohort as to whether they felt this project added value, while limiting stress created. Moreover, this study should be repeated in a non COVID-19 environment, where the stresses of the pandemic are reduced, and classes are resumed in person. This would allow for a comparison of the benefits and successes of the same experiential project to achieve student success in a remote and in an inperson environment.

As a further limitation, it should be noted that while this study indicated their may be correlations between engagement with the experiential activity with academic success (as noted by student achievement of graduate attribute indicators), this study does not directly show that this success is caused by the student engagement with the activity. It is possible that, as a trend, students who would have achieved higher levels of academic success were those who chose to engage with the experiential activity. Future study could examine the extent to which engagement with the project truly causes greater academic success, which could consist of repeating the study in years where entire cohorts are asked to participate rather than having the project be optional. Moreover, although students who participated reported improvements mental health benefits, it is also possible that students who participated in the project had better mental health to begin with. This could also be explored through future study.

This case study outlined the effect of engagement with an experiential project on student success in a virtual format. The relative accessibility of the project combined with the benefits makes it worthy of consideration in future courses where it may be able to enhance the course content. The ability to have experiential learning experiences, specifically away from a computer screen, is especially valuable during virtual learning semesters.

\section{Acknowledgements}

Procedures for ethics were followed which included (though not limited to) rights to withdraw, notification of data collection within the course outline, and maintaining anonymity in data storage. No identifiable markers of institution or students themselves are provided.

\section{REFERENCES}

[1] David A. Kolb, Experiential Learning: Experience as the Source of Learning and Development, Englewood Cliffs, New Jersey: Prentice Hill, 1984, 256 pp. \{ISBN: 0132952610\}

[2] Linda H. Lewis, and Carol J. Williams, "Experiential Learning: Past and Present", New Directions for Adult \& Continuing Edication, no. 62, pp. 5-16, 1994.

[3] Matthew J. Savage, Ruth Janes, Daniele Magistro, James Donaldson, Laura C. Healy, Mary Nevill, and Philip J. Hennis, "Mental Health and Movement Behaviour during the COVID-19 Pandemic in UK University Students: Prospective Cohort Study," Mental Health and Physical Activity, vol. 19, 2020.

[4] Changwon Son, Sudeep Hegde, Alec Smith, Xiaomei Wang, Farzan Sasangohar, "Effects of COVID-19 on College Students' Mental Health in the United States: Interview Survey Study," Journal of Medical Internet Research, vol. 22, no. 9, 2020.

[5] Scott Lee, "Increasing Student Learning: A Comparison of Students' Perceptions of Learning in the Classroom Environment and Their Industry-Based Experiential Learning Assignments", Journal of Teaching in Travel and Tourism, vol. 7, no. 4, pp. 3754, 2007.

[6] Pinaki Chakraborty, Prabhat Mittal, Manu Sheel Gupta, Savita Yadav and Anshika Arora, "Opinion of Students on Online Education during the COVID-19 Pandemic," Human Behavior and Emerging Technologies, In Press, 2020.

[7] D Capranos and L Dyers, Pandemic Response Survey, Orlando, Fl: Wiley Education Services, 2020.

[8] Engineering and Computer Science Association Concordia, Troitsky. Montreal, QC. Available as of March 1, 2021 from https://troitsky.ca/

[9] Bronwyn Chorlton, Natalie Mazur, and John Gales, "Incorporating Timber Education into Existing Accredited Engineering Programs," in Proc. CEEA Canadian Engineering Education Conf., CEEA19, (Ottawa, ON; 8-12 June 2019), 8pp., 2019.

[10] Natalie Mazur, Bronwyn Chorlton and John Gales, "Comparing the Experiences of Women in Engineering Across Different Schools," in Proc. CEEA Canadian Engineering Education Conf., CEEA19, (Ottawa, ON; 8-12 June 2019), 8pp., 2019. 


\section{APPENDIX}

The wording of the exam questions related to the bridge project was as follows:

- Explain any factors that motivated you to participate or not participate in the bridge project.

- If you completed the bridge project, upon completion:

o Do you believe that your participation had any benefits in enhancing your understanding of the course material? Explain.

o Do you believe that your participation had any benefits aside from directly enhancing your understanding of the course material? Explain. 